\title{
Influence of Probiotic Culture Supernatants on In Vitro Biofilm Formation of Staphylococci
}

\author{
Hagen Frickmann ${ }^{1,2^{*}} \uparrow$, Caroline Klenk ${ }^{1} \uparrow$, Philipp Warnke ${ }^{1}$, Sylvio Redanz ${ }^{1,3}$ and Andreas Podbielski ${ }^{1}$ \\ ${ }^{1}$ Institute for Medical Microbiology, Virology and Hygiene, University Medicine Rostock, Rostock, Germany \\ ${ }^{2}$ Department of Microbiology and Hospital Hygiene, Bundeswehr Hospital Hamburg, Hamburg, Germany \\ ${ }^{3}$ Kreth Lab, Department of Restorative Dentistry, Oregon Health \& Science University, Portland, OR, USA
}

Received: 19 August 2018; accepted: 27 August 2018

\begin{abstract}
Background: The effects of cell-free culture supernatants of probiotic Lactobacillus rhamnosus GG and Streptococcus salivarius $\mathrm{K} 12$ on replication and biofilm forming of Staphylococcus aureus and S. epidermidis were assessed in vitro.

Methods: S. aureus and S. epidermidis strains were exposed to cell-free culture supernatants of L. rhamnosus GG and $S$. salivarius $\mathrm{K} 12$ at different concentrations starting at 0,4 , and $24 \mathrm{~h}$ after the onset of incubation. Bacterial amplification was measured on microplate readers, as well as biofilm growth after safranine staining. Scanning electron microscopy was performed for visualization of biofilm status.

Results: The S. salivarius K12 culture supernatant not only reduced or prevented the formation and maturation of fresh biofilms but even caused a reduction of preformed S. epidermidis biofilms. The L. rhamnosus GG culture supernatant did not show clear inhibitory effects regardless of concentration or time of addition of supernatant, and even concentration-depending promotional effects on the planktonic and biofilm growth of S. aureus and S. epidermidis were observed.

Conclusion: In particular, the inhibitory effects of the S. salivarius K12 culture supernatant on the formation of staphylococcal biofilms are of potential relevance for biofilm-associated diseases and should be further assessed by in vivo infection models.
\end{abstract}

Keywords: probiotics, biofilm, Lactobacillus rhamnosus, Streptococcus salivarius, Staphylococcus aureus, Staphylococcus epidermidis, cell-free supernatant, prevention

\section{Introduction}

Cell-free supernatants from microbial cultures were known for decades to show inhibitory effects on the growth of bacteria $[1-7]$. Depending on the bacterial species and clone, as well as on the incubation conditions, highly diverse biologically active substances are secreted and can therefore be detected in the culture supernatant. These include antimicrobial agents, such as bacteriocins [8], and metabolic products, such as organic acids [9], hydrogen peroxide [10], or biosurfactants [11], all with activity against planktonic and biofilmbound bacteria, as well as immunomodulatory substances [12-14]. From a teleological standpoint, it is debatable whether at least some of the abovementioned compounds could be regarded as metabolic waste products with a random activity against other bacterial species or as purposely produced substances to shape the environment of a given bacterium.

For the probiotic bacterium Lactobacillus rhamnosus, culture supernatants exhibit in vitro activity against a number of Gram-positive and Gram-negative bacteria such as Clostridium spp., Enterobacter spp., and staphylococci [15]. In vivo, Lactobacillus rhamnosus GG was shown to temporarily colonize the human gastrointestinal tract [16] with supportive effects in the case of diarrhea in children [17] and curative

\footnotetext{
*Corresponding author: Department of Microbiology and Hospital Hygiene, Bundeswehr Hospital Hamburg, Bernhard Nocht Str. 74, 20359 Hamburg, Germany; E-mail: Frickmann@bni-hamburg.de

$\uparrow$ These authors contributed equally to the manuscript.
}

effects against antibiotic-induced disorders in the gastrointestinal tract [18]. Also, the preventive addition of L. rhamnosus to milk can reduce the risk of developing dental caries [19]. The use of L. rhamnosus GG as a probiotic substance has been extensively assessed regarding its safety profile and is therefore considered as relatively harmless for patients [20]. In vitro studies also provided evidence for L. rhamnosus GG induced effects on biofilm formation in various oral microorganisms [21].

Streptococcus salivarius K12 produces bacteriocin-like inhibitory substances (BLIS). Among these antimicrobial peptides, the lantibiotics, salivaricin A2 and salivaricin B, have been investigated for their biochemical characteristics and functions at a cellular level [22-24]. They inflict growth inhibition on bacteria like Streptococcus pyogenes and Haemophilus influenzae, as well as Candida albicans [25-26]. The preventive use of $S$. salivarius K12 leads to a significantly reduced recurrence of both bacterial and viral pharyngotonsillitis and otitis media [27]. Its use as a probiotic in immunocompetent people is characterized by a good safety profile with reliable antibiotic activity and rare side effects [28].

Sensitivity of staphylococcal biofilms towards antimicrobial peptides has been described [29], although the majority of studies were focused on growth inhibition rather than reduction of formed and differentiated biofilms. In the presented study here, the effects of cell-free culture supernatants of L. rhamnosus $\mathrm{GG}$ and S. salivarius $\mathrm{K} 12$ on both planktonic and biofilm growth of $S$. aureus and $S$. epidermidis strains, as well as their reductive capacity for existing biofilms, were

This is an open-access article distributed under the terms of the Creative Commons Attribution-NonCommercial 4.0 International License (https://creativecommons.org/licenses/by-nc/4.0/), which permits unrestricted use, distribution, and reproduction in any medium for non-commercial purposes, provided the original author and source are credited, a link to the CC License is provided, and changes - if any - are indicated. 
assessed. Compared to former publications, the novel aspects were $S$. salivarius-mediated effects on staphylococci in general and L. rhamnosus-mediated effects on preformed staphylococcal biofilms.

\section{Methods}

Bacterial Strains. Experiments were performed using the strains S. aureus (ATCC 25923), S. epidermidis (ATCC 35984), L. rhamnosus GG (ATCC 53103), and S. salivarius K12 (kindly provided by Dr. J. Tagg, Otago, NZ; see also ref. 26).

Production of Cell-Free Supernatants of Probiotic Bacteria. Overnight cultures of L. rhamnosus GG and $S$. salivarius $\mathrm{K} 12$ were incubated in $18-\mathrm{mL}$ brain heart infusion (BHI) broth (BectonDickinson, Heidelberg, Germany) at $37^{\circ} \mathrm{C}$ and $5 \% \mathrm{CO}_{2}$. Afterwards, centrifugation was performed for $15 \mathrm{~min}$ at $4000 \mathrm{rpm}$ (rotations per minute) at room temperature with subsequent filter sterilization of the recovered culture supernatants using a $0.22-\mu \mathrm{m}$ filter (B. Braun, Melsungen, Germany).

Then, $15 \mathrm{~mL}$ aliquots out of the initial $18-\mathrm{mL}$ volumes were subjected to twice-repeated freeze-drying using a Christ Alpha 1-4 system (Martin Christ Gefriertrocknungsanlagen, Osterode/Harz, Germany). The obtained powder was later dissolved in bi-distilled and autoclaved water to desired concentrations. For comparison, the sterile BHI broth was subjected to these procedures. The $\mathrm{pH}$ values of 10 independent preparations of sterile and spent media were measured with a $\mathrm{pH} 720$ inoLab instrument and a SenTix Microelectrode (WTW, Weilheim, Germany) before and after freeze-drying and reconstitution. In addition, the masses of the freeze-dried substances from 10 independent preparations of sterile and spent media were measured.

General Procedures for Assessing Staphylococcal Growth and Biofilm Formation in the Presence of Cell Free Supernatants. For a gross assessment of potential effects of cell free supernatants on staphylococcal growth, the $S$. epidermidis and $S$. aureus strains were incubated overnight in BHI broth at $37^{\circ} \mathrm{C}$ and under ambient atmosphere. The liquid cultures were adjusted to MacFarland standard of 0.5 by the addition of sterile $0.9 \% \mathrm{NaCl}$ solution, and $100 \mu \mathrm{L}$ aliquots of the bacterial suspensions were spread onto Columbia base agar plates supplemented with 5\% sheep blood (BectonDickinson). Then sterile filter discs with 5-mm diameter were placed onto the inoculated agar surface. On each filter disc, $10 \mu \mathrm{L}$ aliquots of the cell free culture supernatants at 1-fold to 15-fold concentrations were pipetted. The plates were incubated overnight at $37{ }^{\circ} \mathrm{C}$ and ambient atmosphere. The following day, potential growth inhibition zones around the discs were scrutinized by macroscopic inspection.

For assessment of biofilm formation, experiments were performed in 96-well microtiter plates coated with human fibronectin [30] because of an inherent binding affinity of staphylococci to fibronectin [31]. Generally, endpoint measurements of optical density were carried out on a microtiter plate reader.

In the endpoint measurements of bacterial amplification, the transmission of light with a wavelength of $600 \mathrm{~nm}$ (optical density at $600 \mathrm{~nm}=$ OD $600 \mathrm{~nm}$ ) was measured for the bacterial suspensions or media. Based on the absorbance, which correlates with the degree of turbidity of the bacterial culture, the growth of the bacteria in the respective test cavities could be determined.

The readout of the results for biofilm formation by means of safranine staining was carried out analogously. In detail, safranine $\mathrm{O}$ was used for the staining. All wells were rinsed twice with $1 \times$ PBS buffer (Becton Dickinson) by gently pipetting up and down. After a short drying period of $10 \mathrm{~min}$, $200 \mu \mathrm{L}$ of a $0.1 \%$ safranine solution was applied to each test cavity and remained there for $20 \mathrm{~min}$ at room temperature. Subsequently, the described washing process with PBS buffer was repeated. After the cavities had been dried, intensity measurement of the colored cavity bottoms were carried out using the microtiter plate reader at OD $492 \mathrm{~nm}$. The detection limit for biofilm structures was set $>0.05$ for an OD of $492 \mathrm{~nm}$ [32-34].

Quantitative Procedures for Assessing Staphylococcal Growth and Biofilm Formation in the Presence of Spent Media. Planktonic growth and the biofilm formation and masses of $S$. aureus and $S$. epidermidis were investigated by the addition of different concentrations of culture supernatants on the microtiter plate.

On day 1, overnight cultures of $S$. aureus were grown in CASO broth (CB) medium (Carl Roth $\mathrm{GmbH}$, Karlsruhe, Germany) and of $S$. epidermidis in tryptic soy broth (TSB) medium (Becton Dickinson). In parallel, coating of the microtiter plates with human fibronectin was performed.

On day 2, dilution series of 15-fold, 7.5-fold, 3.75-fold, 1.8-fold, 0.9-fold, and 0.46-fold concentrated probiotic cellfree culture supernatants were incubated with $10^{5}$ colony forming units (cfu) per well of the assessed staphylococcal strains.

On day 3, the evaluation was performed in the microtiter plate reader as end point and absorption measurement.

Each series was duplicated as technical replica with 4 biological replicates each. Positive controls (inoculated growth media with supplements of freeze-dried sterile BHI medium) and negative controls (sterile growth media with supplements of freeze-dried sterile spent media) were included.

Experiments on Delayed Application of Culture Supernatants to Biofilm-Associated Staphylococci. To investigate whether the timing of addition of the culture supernatants had an influence on staphylococcal growth, biofilm formation, and masses, the probiotic culture supernatants were added at 0,4 , and $24 \mathrm{~h}$ after the incubation of the bacteria in the test wells had started. The total incubation time for these experiments was $48 \mathrm{~h}$.

On day 1, overnight cultures of staphylococci were grown, and fibronectin coating of the microtiter plates was performed as described above.

On day 2, the bacterial suspensions were prepared using the respective nutrient medium (CB for $S$. aureus and TSB for S. epidermidis) and aliquoted at $100-\mu \mathrm{L}$ volumes (corresponding to $10^{5}$ colony forming units [cfu] per well) in the microtiter plates, except in the case of the negative control.

At the indicated time points, $100 \mu \mathrm{L}$ of a $30 \times$ concentrated probiotic cell-free culture supernatant were added directly to the cavities and cautiously mixed by repeated pipetting. Thus, each well then contained a 1:1 mixture of bacterial culture and culture supernatants in a ratio of $1: 1$ and probiotic culture supernatants in 15-fold concentration.

The incubation at $37{ }^{\circ} \mathrm{C}$ and $5 \% \mathrm{CO}_{2}$ was performed for a total of $48 \mathrm{~h}$ with short breaks at the times of addition of the probiotic cell-free culture supernatant at 4 or $24 \mathrm{~h}$ to the respective wells after the onset of the incubation.

Two specific positive controls were prepared by adding $100 \mu \mathrm{L}$ of the respective sterile freeze-dried growth medium per cavity instead of the probiotic cell-free culture supernatant at time points $0 \mathrm{~h}$ and $24 \mathrm{~h}$ of each experimental series and thus incubated for another $48 \mathrm{~h}$ or $24 \mathrm{~h}$, respectively.

The negative controls, each containing $100 \mu \mathrm{L}$ of sterile medium and $100 \mu \mathrm{L}$ of sterile culture supernatant, were incubated for $48 \mathrm{~h}$.

Statistics. Statistical assessments of the data were performed using the software Microsoft Excel (Microsoft, 
Redmond, WA, USA) and IBM SPSS Statistics (IBM Corporation, New York, USA) applying the two-sided MannWhitney U test. Significance was accepted in the case of $P<$ 0.05 .

Scanning Electron Microscopy (SEM). Scanning electron microscopy (SEM) was performed using a Merlin VP compact system (Carl Zeiss Microscopy GmbH, Jena, Germany) as described by the manufacturer with the following modifications. In detail, cover slips served as sample carriers for the assessment of biofilm growth. The staphylococci were inoculated in uncoated 24-well microtiter plates, each containing a round, sterile, plastic cover slip coated with human fibronectin and were incubated in the absence or presence of cell-free culture supernatants for 24 or $48 \mathrm{~h}$ under aerobic conditions.

After completion of the desired incubation period, the cover slips were carefully removed from the cavities using tweezers, were rinsed once with $1 \times$ PBS, and were afterwards subjected to further sample preparation for scanning electron microscopy as described by Patenge et al. [30].

Ethics. Ethical clearance was not necessary for this study, because neither patient data nor assessments of sample materials from patients were presented.

\section{Results}

Basic Data of the Spent Media Before and After FreezeDrying. As a prerequisite for interpretation of the results, $\mathrm{pH}$ values of the culture supernatants before and after freeze drying as well as the masses of the freeze-dried powder were assessed.

The $\mathrm{pH}$ values from the L. rhamnosus sterile spent media were $5.65 \pm 0.02$ and $5.99 \pm 0.06$, respectively, after filtering but before freeze-drying and after reconstitution of the freezedried substances by addition of sterile water. After freezedrying, a culture volume of $18 \mathrm{~mL}$ resulted in dried powder masses of $561 \pm 30 \mathrm{mg}$. In order to obtain a neutral pH, $234 \pm$ $16 \mu \mathrm{L} 1 \mathrm{~N} \mathrm{NaOH}$ had to be added to the reconstituted spent media.

The corresponding $\mathrm{pH}$ values for the filtered $S$. salivarius spent media were $5.10 \pm 0.00$ and $5.66 \pm 0.06$, respectively, before freeze-drying and after reconstitution. Freeze-drying resulted in powder masses of $530 \pm 20 \mathrm{mg} .285 \pm 24 \mu \mathrm{L} 1 \mathrm{~N}$ $\mathrm{NaOH}$ had to be added for neutralization of the reconstituted culture supernatant. Thus, in terms of the dissolved powder masses, the concentrations of the reconstituted cell free culture supernatants used in the experiments for both bacterial species varied approximately between 17 ( 0.45 -fold concentration) and 560 (15-fold concentration) g/L.

When subjecting the sterile culture media to the same procedures as the spent media, before sterile filtering the $\mathrm{pH}$ values were $7.54 \pm 0.03$ and $7.30 \pm 0.02$ before freeze-drying and after reconstitution, respectively, with a mass of $740 \pm 12$ mg of the dried powder. After sterile filtering the corresponding $\mathrm{pH}$ values were $7.49 \pm 0.02$ and $7.15 \pm 0.01$, respectively, and the dried powder mass was $530 \pm 30 \mathrm{mg}$. For neutralization of the reconstituted media, 15 or $50 \mu \mathrm{L} 1 \mathrm{~N} \mathrm{NaOH}$, respectively, had to be added when prepared before or after sterile filtering.

The different amounts of basic fluid needed for neutralization of media before and after filtering and before and after freeze-drying indicated that the filters absorbed some basic molecules while freeze-drying evaporated some acidic molecules.

Quantitative Growth Inhibition Measurements. When using the reconstituted culture supernatants for classical agar diffusion assay techniques, no inhibition zones could be recorded around the impregnated filter discs irrespective of the concentrations of the cell free culture supernatants used in this experiment (data not shown). Therefore, the more refined technique described below was used for further analysis.

At all but the highest concentration of L. rhamnosus GG culture supernatant, the ODs of $S$. aureus cultures rose with increasing concentration. Using 15-fold concentrated supernatant, the OD of $S$. aureus culture was lower than that in the associated positive control. By measuring the absorbance of the safranine dye, an OD $492 \mathrm{~nm}>0.05$ suggesting biofilm growth could be detected for each amount of culture supernatants added to the assay. Only when using culture supernatants at the maximum concentration, the biofilm mass was lower than that in the positive control (Table 1; Figure 1).

In turn, when $S$. aureus cultures were incubated with $S$. salivarius K12 supernatant, an inhibitory effect as demonstrated by low optical density (OD $600 \mathrm{~nm}$ ) could be observed already for the use of 1.8-fold concentrated culture supernatant. The effect correlated to the amount of supernatants except for the 15 -fold concentrate. The relationship between increasing concentration of the culture supernatant and decreasing biofilm mass was already visible for the lowest concentration of the culture supernatant and stayed consistent across all concentration levels (Table 1; Figure 2).

Table 1. Measured optical densities in cased of different concentrations of culture supernatant (n.s. = not significant)

\begin{tabular}{|c|c|c|c|c|c|c|c|c|}
\hline on & $\mathrm{d}$ & 7.5 & $d$ & 1.8 & 0.9 & 0.4 & $\begin{array}{l}\text { Positive } \\
\text { control }\end{array}$ & $\begin{array}{l}\text { Negative } \\
\text { control }\end{array}$ \\
\hline \multicolumn{9}{|c|}{$\begin{array}{l}\text { Measurement of optical density (OD) at } 600 \mathrm{~nm} \text { to assess planktonic growth (OD values } \pm \text { standard deviation) }(P=\text { significance level compared with } \\
\text { positive control; n.s. = not significant) }\end{array}$} \\
\hline a & $\begin{array}{l}0.62 \pm 0 . \\
\text { n.s. }\end{array}$ & $\begin{array}{l}0.33= \\
P<\end{array}$ & $\begin{array}{c}0.28 \\
P\end{array}$ & $\begin{array}{l}0.53 \\
P<\end{array}$ & $\begin{array}{l}0.64 \pm 0 . \\
\text { n.s. }\end{array}$ & $\begin{array}{r}0.61 \pm \\
\mathrm{n}\end{array}$ & $\begin{array}{l}0.07 ; \\
\text { nce }\end{array}$ & $\begin{array}{c}0.46 \\
P\end{array}$ \\
\hline h & $\begin{array}{r}0.77 \pm \\
\mathrm{n}\end{array}$ & $\begin{array}{c}1.08 \\
P<\end{array}$ & $\begin{array}{l}0.86 \\
P<\end{array}$ & $\begin{array}{r}0.75 \\
P<\end{array}$ & $\begin{array}{c}0.67 \pm 0 . \\
\text { n.s. }\end{array}$ & $\begin{array}{c}0.61 \pm 0.06 \\
\text { n.s. }\end{array}$ & $\begin{array}{l}0.04 ; \\
\text { nce }\end{array}$ & $\begin{array}{l}0.40 \\
P<\end{array}$ \\
\hline $\begin{array}{l}\text { lis } \text { culture with } \\
\text { K12 supernatant }\end{array}$ & $\begin{array}{c}0.40 \pm 0.06 \\
P<0.001\end{array}$ & $\begin{array}{c}0.30 \pm 0.05 \\
P<0.001\end{array}$ & $\begin{array}{c}0.53 \pm 0.08 \\
P<0.01\end{array}$ & $\begin{array}{c}0.69 \pm 0.06 \\
P<0.05\end{array}$ & $\begin{array}{c}0.62 \pm 0.07 \\
\text { n.s. }\end{array}$ & $\begin{array}{c}0.57 \pm 0.18 \\
\text { n.s. }\end{array}$ & $\begin{array}{l}0.03 \text {; } \\
\text { ence }\end{array}$ & $\begin{array}{c}0.45 \\
P<\end{array}$ \\
\hline \multicolumn{9}{|c|}{$\begin{array}{l}\text { Measurement of optical density (OD) at } 492 \mathrm{~nm} \text { to assess biofilm growth (OD values } \pm \text { standard deviation) }(P=\text { significance level compared with } \\
\text { positive control; n.s. = not significant) }\end{array}$} \\
\hline aur & $\begin{array}{l}0.11= \\
P<\end{array}$ & $0.73=$ & $0.36=$ & 0.71 & 0.52 & $0.57 \pm$ & $\begin{array}{l}0.68 \text {; } \\
\text { nce }\end{array}$ & $\begin{array}{l}0.05 \\
P<\end{array}$ \\
\hline n & $\begin{array}{c}0.04= \\
P<\end{array}$ & $\begin{array}{r}0.02 \\
P<\end{array}$ & $\begin{array}{l}0.03 \\
P<\end{array}$ & $\begin{array}{r}0.13= \\
n\end{array}$ & $\begin{array}{r}0.19= \\
n\end{array}$ & $\begin{array}{r}0.24 \pm \\
n\end{array}$ & $\begin{array}{l}0.57 \text {; } \\
\text { nce }\end{array}$ & 01 \\
\hline $\begin{array}{l}\text { S. epidermidis culture with } \\
\text { S. salivarius } \mathrm{K} 12 \text { supernatant }\end{array}$ & $\begin{array}{c}0.03 \pm 0.02 \\
P<0.001\end{array}$ & $\begin{array}{c}0.03 \pm 0.02 \\
P<0.001\end{array}$ & $\begin{array}{l}0.28 \pm 0.19 \\
\text { n.s. }\end{array}$ & $\begin{array}{c}0.11 \pm 0.04 \\
P<0.001\end{array}$ & $\begin{array}{c}0.06 \pm 0.02 \\
P<0.001\end{array}$ & $\begin{array}{c}0.15 \pm 0.07 \\
P<0.01\end{array}$ & $\begin{array}{l}0.33 \pm 0.09 \\
\text { reference }\end{array}$ & $\begin{array}{c}0.06 \pm 0.03 \\
P<0.001\end{array}$ \\
\hline
\end{tabular}




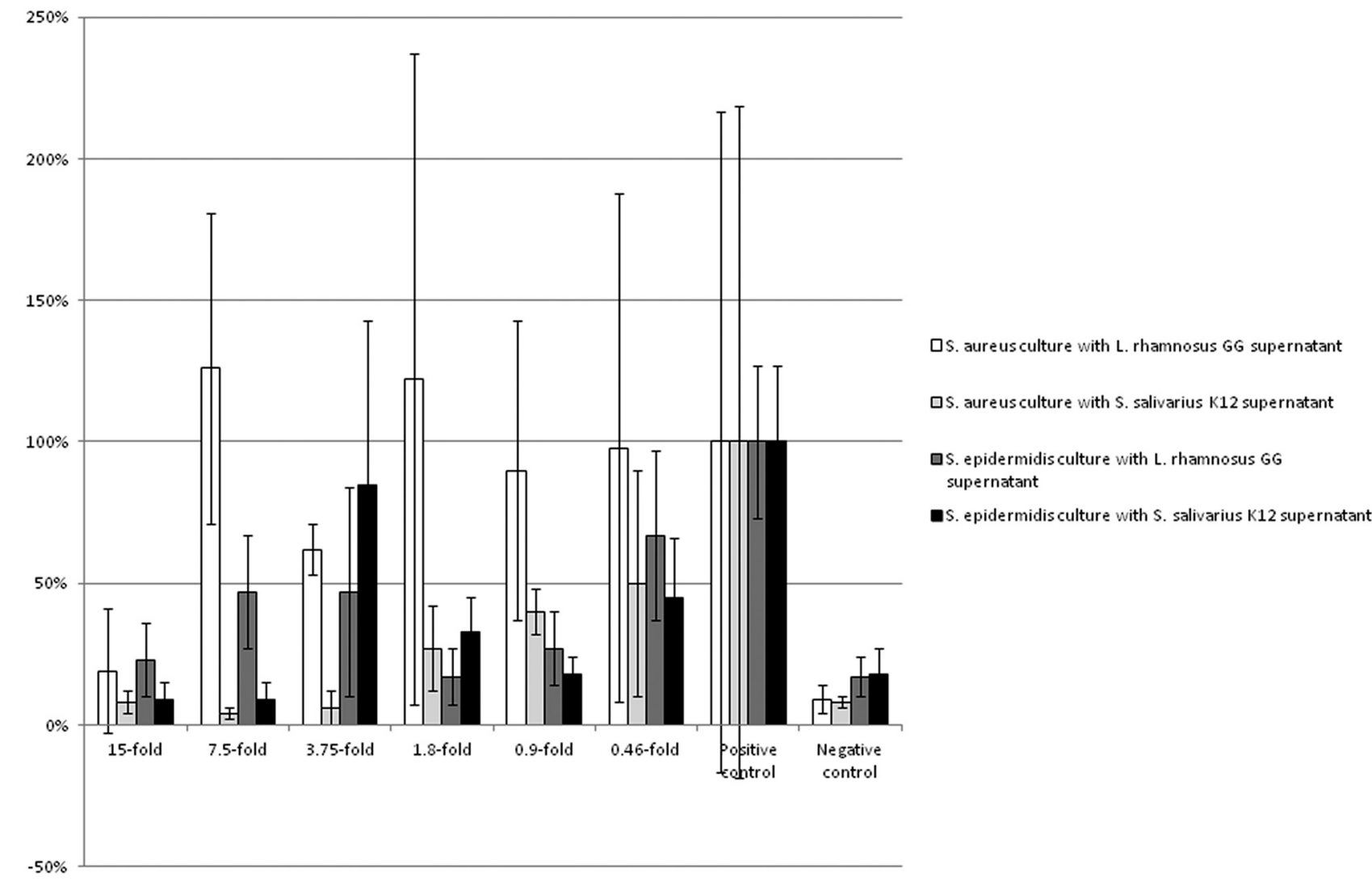

Figure 1. Measured optical densities in the case of different concentrations of culture supernatants. Measurement of optical density (OD) at $492 \mathrm{~nm}$ to assess biofilm growth (OD values \pm standard deviation)

When the L. rhamnosus GG culture supernatant was used on $S$. epidermidis cultures, they grew to a higher optical density than that in the positive control wells. Up to a 7.5 -fold concentration, this effect increased steadily. Then, only at 15-fold concentration, it dropped again. The use of the L. rhamnosus GG culture supernatant resulted in reduced

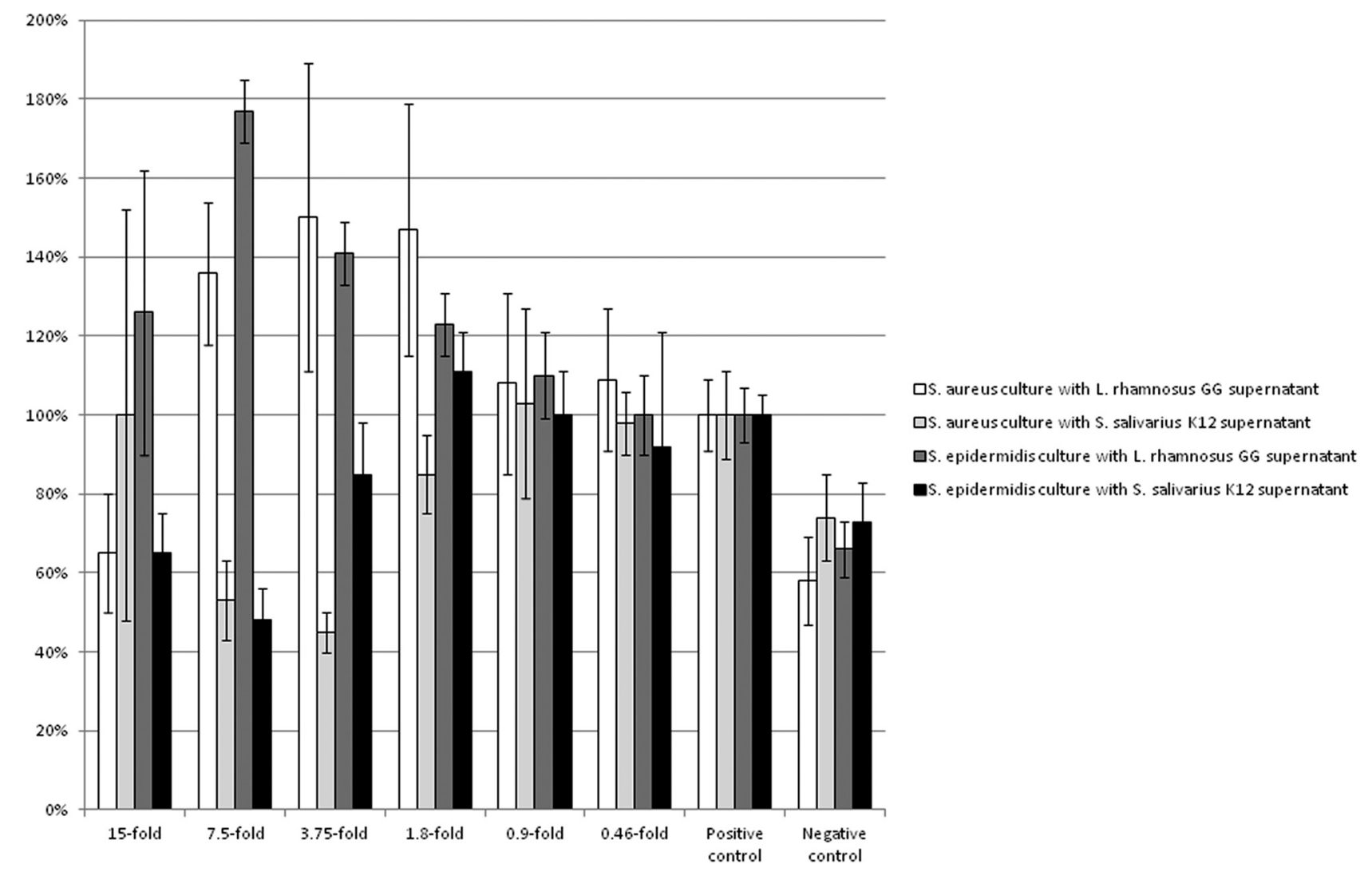

Figure 2. Measured optical densities in the case of different concentrations of culture supernatants. Measurement of optical density (OD) at $600 \mathrm{~nm}$ to assess planktonic growth (OD values \pm standard deviation) 
biofilm growth compared to the positive control. However, varying and even contradictory effects were observed for different concentrations of supernatants (Table 1; Figure 1).

According to measurement results of the OD $600 \mathrm{~nm}$, $S$. epidermidis growth with the $S$. salivarius K12 culture supernatant suggested a tendency for a concentration-dependent effect. Small amounts of culture supernatants had no or even a slight growth-promoting effect. But from 3.75-fold concentration on, an increasingly growth-inhibiting influence was observed. Biofilm formation was obviously reduced due to culture supernatant, and this effect increased with increasing concentrations of the $S$. salivarius K12 culture supernatant in spite of the outlier at 3.75-fold concentration (Table 1; Figure 2).

Experiments on Delayed Application of Culture Supernatants. Overall, co-incubation with the L. rhamnosus GG culture supernatant resulted in a significantly higher optical density of the $S$. aureus culture than that in the positive controls. This effect was consistent for all three addition times. This observation for bacterial amplification rates correlated with the results for biofilm formation. Increased planktonic and biofilm growth of $S$. aureus after addition of the L. rhamnosus GG supernatant was observed independently of the time of addition to the medium (Table 2; Figures 3 and 4).

Upon early addition of the $S$. salivarius K12 culture supernatant to the $S$. aureus culture at 0 and $4 \mathrm{~h}$ after the start of culture, respectively, there was a considerably lower optical density compared to both positive controls. If the addition occurred $24 \mathrm{~h}$ after the onset of culture, then the optical density of the $S$. aureus culture was higher compared to that for earlier addition time-points, but still lower than that of the positive control incubated for $48 \mathrm{~h}$.

In the case of immediate addition of the $S$. salivarius K12 culture supernatant and in the case of 4-h latency of addition to the $S$. aureus culture, no biofilm formed by $S$. aureus could be detected. Associated absorption measurements at OD $462 \mathrm{~nm}$ were lower than those of the positive controls after 24 or $48 \mathrm{~h}$ of incubation. Only the addition of culture supernatants after previous incubation of the $S$. aureus culture for $24 \mathrm{~h}$ resulted in increased biofilm mass in comparison to the positive control that was incubated for $48 \mathrm{~h}$ (Table 2, Figure 3).

Irrespective of the time point, a higher optical density compared to the positive controls resulted in the addition of the L. rhamnosus GG culture supernatant to $S$. epidermidis cultures. S. epidermidis grew independently of the time of addition of supernatants in the form of a biofilm. The biofilm mass was reduced compared to the positive controls when supernatants were added immediately or $4 \mathrm{~h}$ after the start of incubation but it was increased if a supernatant was added with 24-h latency (Table 2, Figure 3).

The optical density of $S$. epidermidis cultures varied with the time of $S$. salivarius K12 addition. The lowest OD values were measured in the case of immediate and 4-h-delayed addition of the culture supernatant to the $S$. epidermidis culture. These values were lower compared to those of the two positive controls. If the addition of the supernatant occurred with 24-h latency, the optical density of the culture at the end of the study was higher than that in case of earlier addition, but still lower than that of the $24-\mathrm{h}$ positive control. At all times of addition of supernatant, reduced absorption values were measured at OD $462 \mathrm{~nm}$. If the addition was made immediately or after $4 \mathrm{~h}$, no biofilm growth could be detected. Biofilms could be detected in the case of an addition of the culture supernatant that was delayed by $24 \mathrm{~h}$, but this biofilm still had less mass than the biofilms in the control samples. In comparison with the 24-h positive control, a reduction of an already preformed biofilm was demonstrated (Table 2, Figure 3).

Scanning Electron Microscopy (SEM). Biofilms could be demonstrated for all experimental settings with the exception of co-incubation of staphylococci with the S. salivarius K12 supernatant at 15 -fold concentration that was added immediately or $4 \mathrm{~h}$ after the onset of incubation (Figure $5 \mathrm{~A}$ ). Examples of weak (Figure 5B) and strong (Figure 5C, D) biofilm growth are presented to visualize the above described quantitative effects of the cell-free culture supernatants.

Table 2. Measured optical densities after delayed application of culture supernatant (n.s. = not significant)

\begin{tabular}{|c|c|c|c|c|c|c|}
\hline & $\begin{array}{l}\text { 0-h delay of application } \\
\text { (measurement after } 48 \mathrm{~h} \text { ) }\end{array}$ & $\begin{array}{l}\text { 4-h delay of application } \\
\text { (measurement after } 48 \mathrm{~h} \text { ) }\end{array}$ & $\begin{array}{l}\text { 24-h delay of application } \\
\text { (measurement after } 48 \mathrm{~h} \text { ) }\end{array}$ & $\begin{array}{l}\text { 24-h positive } \\
\text { control }\end{array}$ & $\begin{array}{l}\text { 48-h positive } \\
\text { control }\end{array}$ & $\begin{array}{c}\text { 48-h negative } \\
\text { control }\end{array}$ \\
\hline \multicolumn{7}{|c|}{$\begin{array}{l}\text { Measurement of optical density (OD) at } 600 \mathrm{~nm} \text { to assess planktonic growth (OD values } \pm \text { standard deviation) }\left(P_{24}=\text { significance level compared with } 24-\mathrm{h}\right. \\
\left.\text { positive control; } P_{48}=\text { significance level compared with } 48 \text {-h positive control; n.s. }=\text { not significant }\right)\end{array}$} \\
\hline L. rhamnosus GG supernatant & $\begin{array}{l}P_{24}<0.001 \\
P_{48}=\text { n.s. }\end{array}$ & $\begin{array}{l}P_{24}<0.001 \\
P_{48}=\text { n.s. }\end{array}$ & $\begin{array}{l}P_{24}<0.001 \\
P_{48}<0.05\end{array}$ & reference $24 \mathrm{~h}$ & reference $48 \mathrm{~h}$ & $\begin{array}{l}\text { significance } \\
\text { not assessed }\end{array}$ \\
\hline S. aureus culture with & $0.32 \pm 0.03$ & $0.34 \pm 0.03$ & $0.77 \pm 0.15$ & $0.55 \pm 0.12$ & $0.97 \pm 0.19$ & $0.37 \pm 0.08$ \\
\hline S. salivarius $\mathrm{K} 12$ supernatant & $\begin{array}{l}P_{24}<0.001 \\
P_{48}<0.001\end{array}$ & $\begin{array}{l}P_{24}<0.001 \\
P_{48}<0.001\end{array}$ & $\begin{array}{c}\mathrm{P}<0.01 \\
P_{24}<0.01 \\
P_{48}<0.05\end{array}$ & reference $24 \mathrm{~h}$ & reference $48 \mathrm{~h}$ & $\begin{array}{l}\text { significance } \\
\text { not assessed }\end{array}$ \\
\hline S. epidermidis culture with & $1.13 \pm 0.14$ & $1.17 \pm 0.05$ & $1.18 \pm 0.09$ & $0.74 \pm 0.12$ & $0.64 \pm 0.11$ & $=0.07$ \\
\hline L. rhamnosus GG supernatant & $\begin{array}{l}P_{24}<0.001 \\
P_{48}<0.001\end{array}$ & $\begin{array}{l}P_{24}<0.001 \\
P_{48}<0.001\end{array}$ & $\begin{array}{l}P_{24}< \\
P_{48}<\end{array}$ & reference $24 \mathrm{~h}$ & reference $48 \mathrm{~h}$ & $\begin{array}{l}\text { significance } \\
\text { not assessed }\end{array}$ \\
\hline S. epidermidis culture with & $0.33 \pm 0.06$ & $0.36 \pm 0.03$ & $0.56 \pm 0.10$ & $0.74 \pm 0.12$ & $0.64 \pm 0.11$ & $0.39 \pm 0.07$ \\
\hline S. salivarius $\mathrm{K} 12$ supernatant & $\begin{array}{l}P_{24}<0.001 \\
P_{48}<0.001\end{array}$ & $\begin{array}{l}P_{24}<0.001 \\
P_{48}<0.001\end{array}$ & $\begin{array}{l}P_{24}<0.01 \\
P_{48}=\text { n.s. }\end{array}$ & reference $24 \mathrm{~h}$ & reference $48 \mathrm{~h}$ & $\begin{array}{l}\text { significance } \\
\text { not assessed }\end{array}$ \\
\hline \multicolumn{7}{|c|}{$\begin{array}{l}\text { Measurement of optical density (OD) at } 492 \mathrm{~nm} \text { to assess biofilm growth }(\mathrm{OD} \text { values } \pm \text { standard deviation })\left(P_{24}=\text { significance level compared with } 24-\right. \\
\text { positive control; } P_{48}=\text { significance level compared with } 48 \text {-h positive control; n.s. }=\text { not significant) }\end{array}$} \\
\hline S. aureus culture with & $0.32 \pm 0.20$ & $0.40 \pm 0.26$ & $0.47 \pm 0.34$ & $0.10 \pm 0.01$ & $0.09 \pm 0.03$ & $0.06 \pm 0.03$ \\
\hline L. rhamnosus GG supernatant & $\begin{aligned} P_{24}<0.001 \\
P_{48}<0.001\end{aligned}$ & $\begin{array}{l}P_{24}<0.001 \\
P_{48}<0.001\end{array}$ & $\begin{array}{l}P_{24}<0.01 \\
P_{48}<0.01\end{array}$ & referes & reference $48 \mathrm{~h}$ & $\begin{array}{l}\text { significance } \\
\text { not assessed }\end{array}$ \\
\hline S. aureus culture with & $0.02 \pm 0.01$ & $0.03 \pm 0.01$ & $0.17 \pm 0.09$ & $0.10=$ & $0.09 \pm 0.03$ & $0.06 \pm 0.03$ \\
\hline S. salivarius $\mathrm{K} 12$ supernatant & $\begin{array}{l}P_{24}<0.001 \\
P_{48}<0.001\end{array}$ & $\begin{array}{l}P_{24}<0.001 \\
P_{48}<0.001\end{array}$ & $\begin{aligned} P_{24} & <0.05 \\
P_{48} & <0.05\end{aligned}$ & referen & reference $48 \mathrm{~h}$ & $\begin{array}{l}\text { significance } \\
\text { not assessed }\end{array}$ \\
\hline S. epidermidis culture with & $0.14 \pm 0.01$ & $0.18 \pm 0.18$ & $0.28 \pm 0.19$ & $0.24 \pm 0.07$ & $0.24 \pm 0.08$ & $0.07 \pm 0.04$ \\
\hline L. rhamnosus GG supernatant & $\begin{array}{l}P_{24}<0.05 \\
P_{48}<0.05\end{array}$ & $\begin{array}{l}P_{24}=\text { n.s.; } \\
P_{48}=\text { n.s. }\end{array}$ & $\begin{array}{l}P_{24}=\text { n.s.; } \\
P_{48}=\text { n.s. }\end{array}$ & reference $24 \mathrm{~h}$ & reference $48 \mathrm{~h}$ & $\begin{array}{l}\text { significance } \\
\text { not assessed }\end{array}$ \\
\hline S. epidermidis culture with & $0.03 \pm 0.01$ & $0.03 \pm 0.01$ & $0.12 \pm 0.06$ & $0.24 \pm 0.07$ & $0.24 \pm 0.08$ & $0.07 \pm 0.04$ \\
\hline S. salivarius $\mathrm{K} 12$ supernatant & $\begin{aligned} P_{24} & <0.001 \\
P_{48} & <0.001\end{aligned}$ & $\begin{aligned} P_{24} & <0.001 \\
P_{48} & <0.001\end{aligned}$ & $\begin{array}{l}P_{24}<0.01 \\
P_{48}<0.01\end{array}$ & reference $24 \mathrm{~h}$ & reference $48 \mathrm{~h}$ & $\begin{array}{l}\text { significance } \\
\text { not assessed }\end{array}$ \\
\hline
\end{tabular}




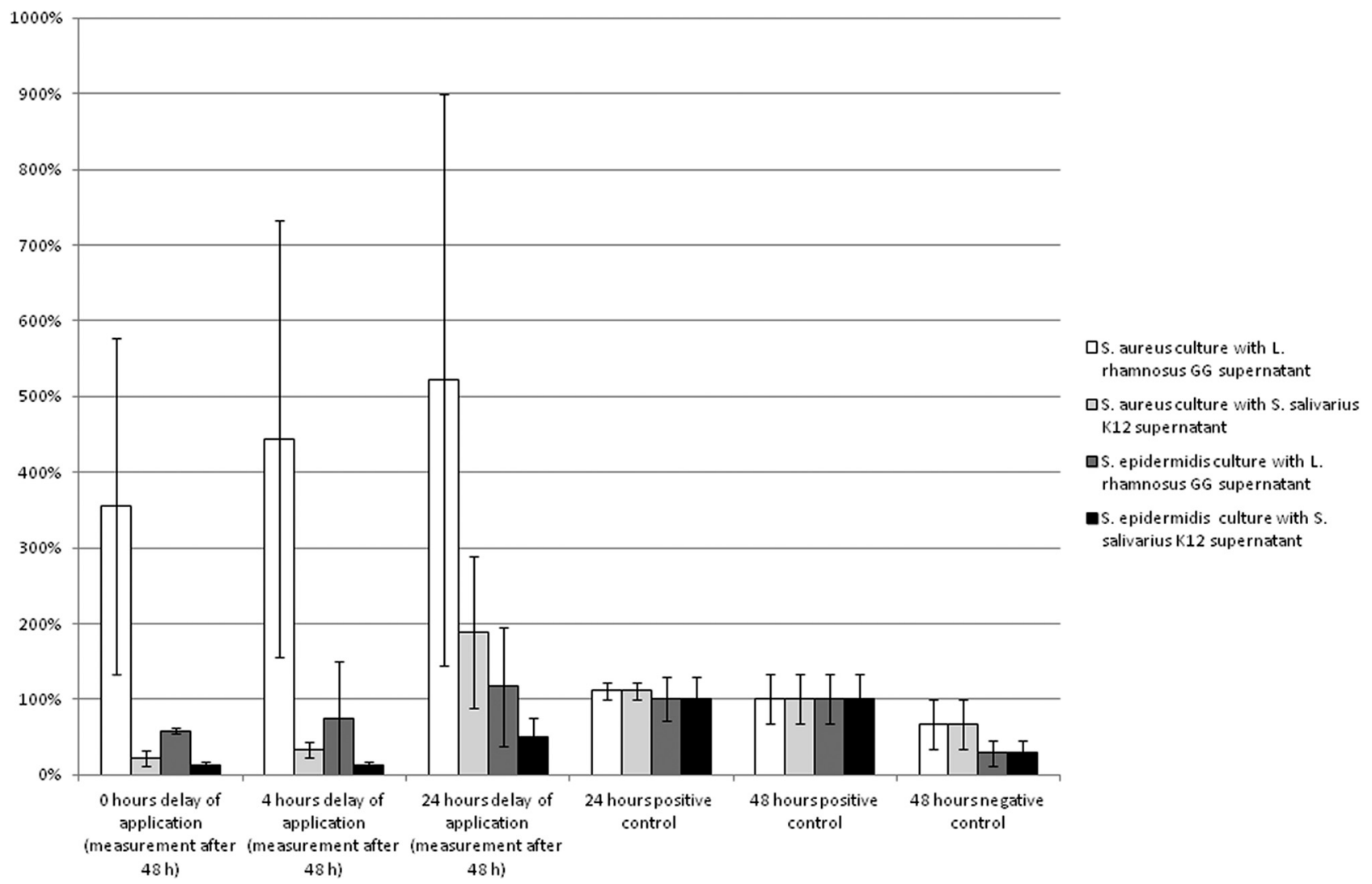

Figure 3. Measured optical densities after delayed application of culture supernatants. Measurement of optical density (OD) at $492 \mathrm{~nm}$ to assess biofilm growth (OD values \pm standard deviation)

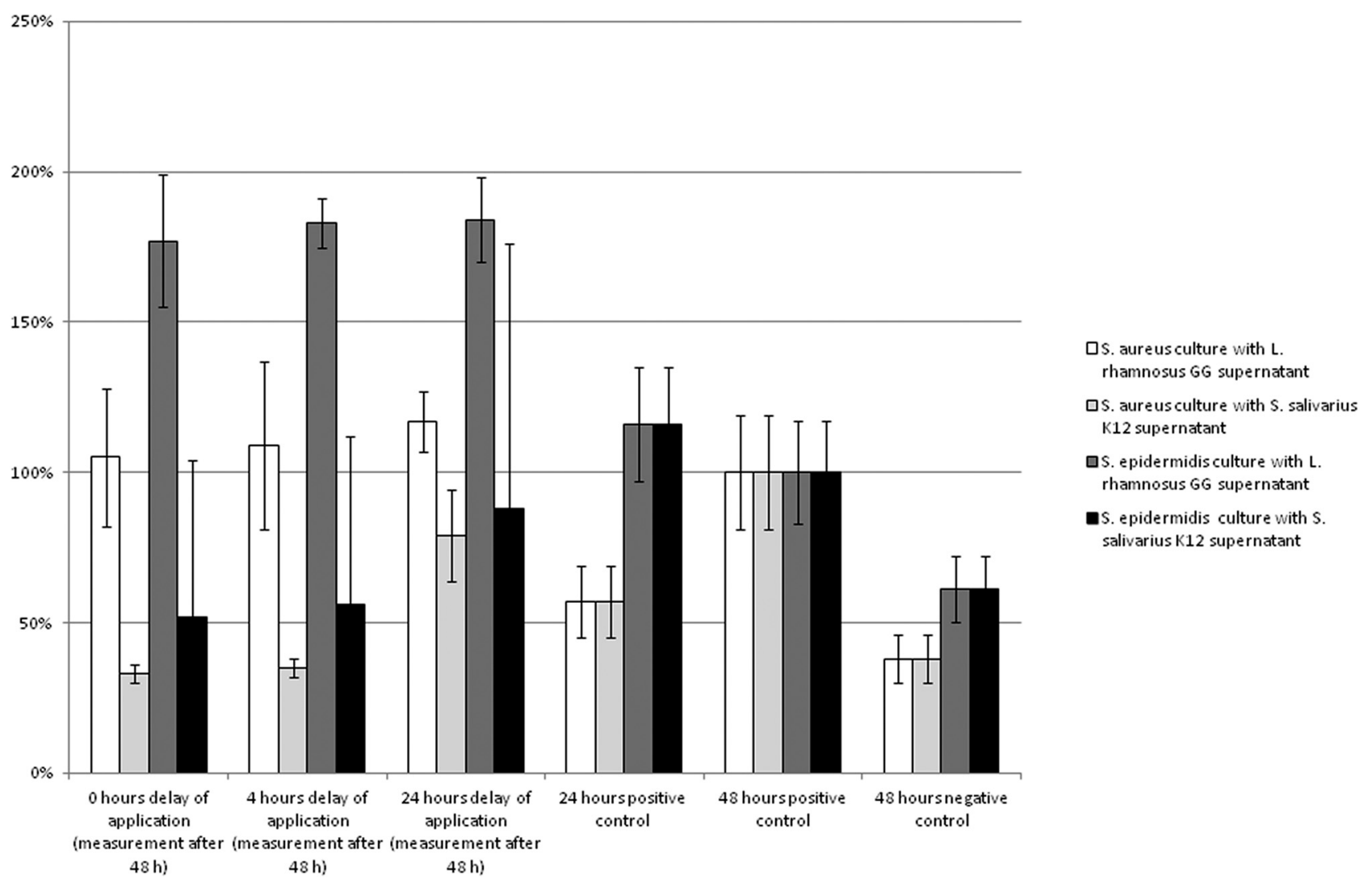

Figure 4. Measured optical densities after delayed application of culture supernatant. Measurement of optical density (OD) at $600 \mathrm{~nm}$ to assess planktonic growth (OD values \pm standard deviation) 


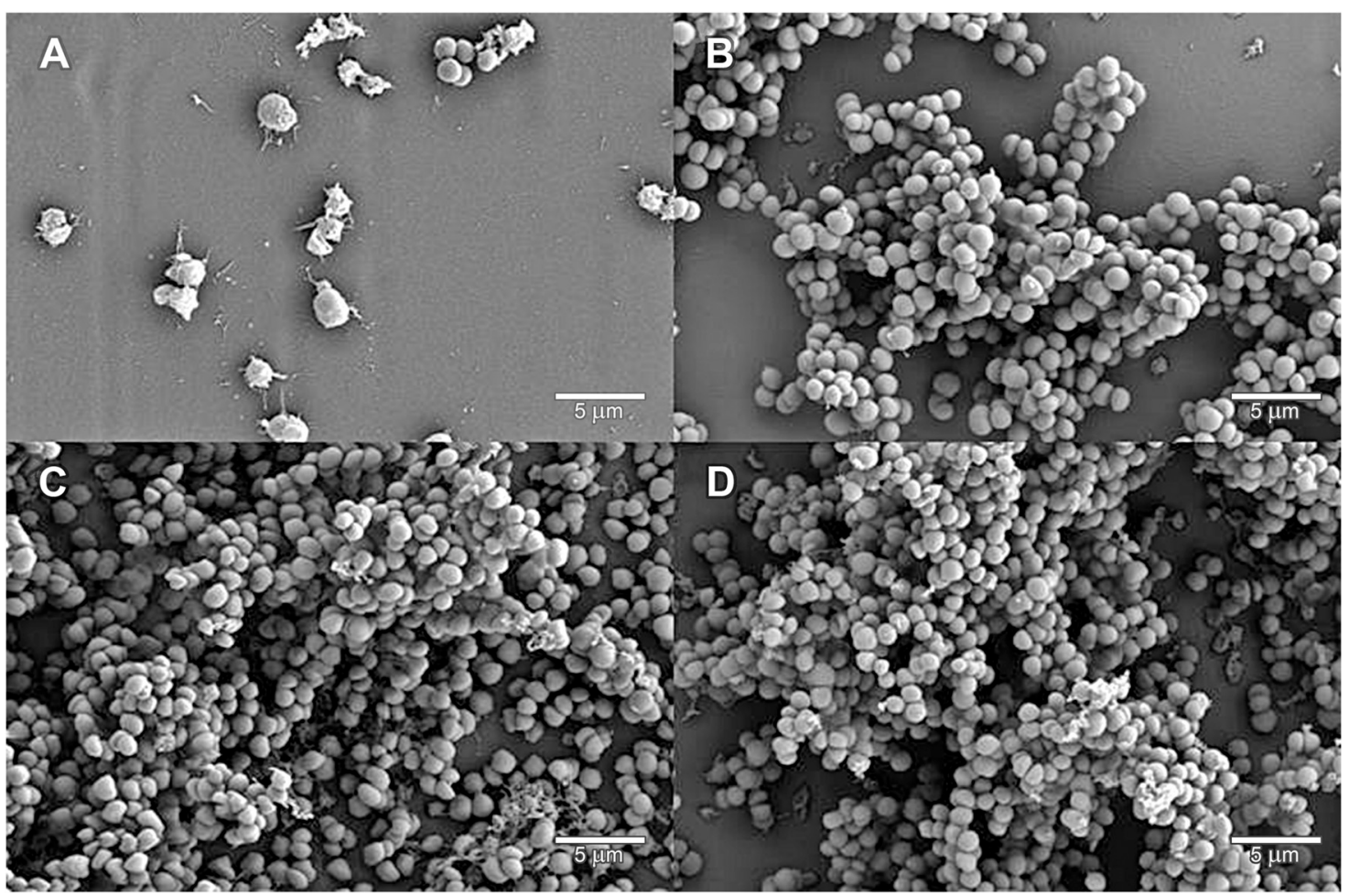

Figure 5. Exemplary demonstration of biofilm growth using SEM. (A) Absence of biofilm in the case of co-incubation of S. epidermidis with the S. salivarius K12 supernatant at 15 -fold concentration that was added immediately after the onset of incubation. (B) Weak biofilm formation in the case of co-incubation of S. epidermidis with the S. salivarius K12 supernatant at 15 -fold concentration that was added $24 \mathrm{~h}$ after the onset of incubation. (C and D) Intense biofilm growth of S. epidermidis in the positive control samples, which were incubated without the $S$. salivarius K12 supernatant, $24 \mathrm{~h}$ and $48 \mathrm{~h}$ after the onset of incubation, respectively. Magnification: $5000 \times$

\section{Discussion}

This study focused on the identification and quantification of inhibitory effects (minimum inhibitory concentration [MIC]) of culture supernatants from established probiotic bacteria on planktonic and biofilm growth of staphylococci. Similar to susceptibility testing of bacteria to antibiotics, experiments were carried out to identify gross inhibitory effects and, thereafter, the minimum inhibitory concentration of probiotic culture supernatants. Not only the detection of an inhibitory effect of the culture supernatants per se but also the necessary concentration and the optimal time of addition were of interest in these experiments. Furthermore, in contrast to conventional antibiotic susceptibility testing, not only the effect on planktonic bacterial growth was investigated, but special attention was also given to biofilm growth.

The results of the influence of culture supernatants on the planktonic forms of both assessed Staphylococcus species, i.e., S. aureus and S. epidermidis, could represent genus-wide effects due to the similarity of results for strains of both species. The L. rhamnosus GG culture supernatant increased the optical density of staphylococcal cultures, while the S. salivarius K12 culture supernatant reduced their optical density.

Regardless of the time of delayed addition of L. rhamnosus GG culture supernatant, generally there was a mild growthpromoting effect for $S$. aureus and a pronounced one for $S$. epidermidis. On the other hand, the S. salivarius $\mathrm{K} 12$ culture supernatant was able to inhibit both staphylococcal cultures in the case of early addition. After 24-h latency of the addition, a slight inhibitory effect could still be noted.

In addition to the observations for the planktonic form of S. aureus and S. epidermidis, a species-specific but also concentration-dependent effect was observed regarding the influence on biofilm formation in the MIC experiments. Overall, the addition of L. rhamnosus GG and S. salivarius K12 culture supernatants resulted in markedly reduced $S$. epidermidis biofilm growth. The two highest concentrations of the $S$. salivarius K12 culture supernatant thoroughly suppressed biofilm formation.

In contrast, this reducing or suppressing effect on $S$. aureus biofilm formation was observed only when using the $S$. salivarius $\mathrm{K} 12$ culture supernatant. The $L$. rhamnosus GG culture supernatant did show ambiguous effects on biofilms formed by $S$. aureus.

Focusing on time-dependent influences on the formation of biofilms in the presence of the L. rhamnosus GG culture supernatant, an increasingly growth-promoting effect on $S$. aureus biofilms was seen in the case of increasingly delayed addition in comparison to low biofilm masses in the positive controls. One potential explanation for the low biofilm masses in the positive controls may be the detachment of the biofilm as part of the washing steps prior to staining with safranine [35]. Although there is no general recommendation on the number of washing steps to be performed, two steps are usually considered to be the absolute minimum and have therefore been used in this study [31-33, 36-38]. Also, some inconsistencies between the concentrations of the applied spent media and their activities on biofilm masses may result from the safranine staining technique. As recently shown [39-40], extraction of stains from air-dried biofilms and subsequent measurements of the supernatants as opposed to direct measurements of the in-situ stained biofilms could be the superior technique.

The L. rhamnosus GG culture supernatant promoted the biofilm formation of $S$. epidermidis after a 24-h lag compared to the onset of cultural growth of the staphylococci in the experiment. In contrast, also at other time points, the $S$. salivarius K12 culture supernatant demonstrated marked inhibitory effects. In the case of early addition, biofilm growth was suppressed for both $S$. aureus and $S$. epidermidis by $S$. salivarius K12 culture supernatant. For $S$. aureus, this reduction effect 
was no longer detectable when added with 24-h latency, whereas it could still be confirmed for S. epidermidis. This apparently subsequent reduction of the biofilm mass due to culture supernatants could be caused by destabilization and subsequent release of the loosened biofilm, which is promoted by the washing steps [41].

The scanning electron microscopic evaluation of the biofilm formation allowed the direct visualization of the grown biofilm and thus supported the determined quantitative results. Only the two highest concentrations of the co-administered S. salivarius $\mathrm{K} 12$ culture supernatant were associated with undetectable biofilms, while biofilms were formed by S. aureus and $S$. epidermidis at all time points of investigation upon addition of the L. rhamnosus GG culture supernatant.

The main findings, namely, the proof of a concentrationdependent and time-dependent effect of probiotic culture supernatants on planktonic and biofilm growth of staphylococci, correspond to the results in the literature in particular for S. salivarius K12. The observed increased effect by higher concentrations of the culture supernatants was also described by others $[2,14,42]$. Further, the inhibitory effect largely depends on the status of the biofilm. Generally, it seems to be much easier to achieve effects on fresh biofilms than on already grown and matured ones as previously suggested elsewhere [43].

This study did not analyze the molecular background of the observed growth inhibiting and biofilm-dissolving effects of the probiotic culture supernatants. The acidic $\mathrm{pH}$ values of the spent media could be an explanation, since acidification has a long standing tradition, e.g., for prevention of staphylococcal food poisoning [44]. Systematic neutralization, e.g., by adding sodium hydroxide to all supernatants, was not performed, an admitted limitation of the study. However, both probiotic bacterial strains acidify their culture supernatants, but the application of their spent media displayed marked differences in terms of the exposed bacterial species and their status as being planktonic or biofilm-associated. As mentioned above, probiotic antibacterial activity relies on several modes of action, and the present results point in that direction as well.

Probiotic bacteria have successfully been used on a routine basis to fight the growth of staphylococci in the human environment or on human mucosal surfaces [44]. In contrast, counteracting established staphylococcal biofilms still remains at an experimental level [45]. Since therapy in a real clinical scenario usually has to deal with already existing biofilms, the effect of a substance or a mix of substances which reduce an existing biofilm mass would be extremely valuable. However, this goal has not been satisfyingly reached irrespective of the application methods or compounds utilized so far [46-50]. Alternatively, the inhibitory effect on the growth of fresh biofilms could be used and even plays a role in implant materials that have been covered by biofilm-reducing substances [51, 52]. For this reason, probiotic bacteria or antimicrobials secreted by them into the culture supernatants could be used both for preventive and therapeutic purposes. Probiotic culture supernatants as described in this study, mainly the supernatants of S. salivarius K12, should be prospectively tested for their antimicrobial properties in in vivo models of implant infections.

\section{Conclusions}

Time and concentration-depending effects of cell-free supernatants of the probiotic bacteria L. rhamnsosus GG and S. salivarius $\mathrm{K} 12$ on amplification and biofilm formation of staphylococci could be confirmed. The growth-inhibiting effects of the $S$. salivarius K12 supernatants were more pronounced. The mode of action appears to rely on more than just acidification of the growth media.

\section{Funding Sources}

There has been no source of funding.

\section{Authors' Contribution}

$\mathrm{HF}$ and AP wrote the article. CK performed the experiments. PW, SR, and AP planned the study and supervised the experiments. All authors have read and corrected the article prior to publication.

\section{Conflict of Interest}

There is no conflict of interest to report.

\section{References}

1. Mariam SH, Zegeye N, Aseffa A, Howe R. Diffusible substances from lactic acid bacterial cultures exert strong inhibitory effects on Listeria monocytogenes and Salmonella enterica serovar Enteritidis in a co-culture model. BMC Microbiol. 2017;17:35.

2. Melo TA, Dos Santos TF, Almeida MEde, Junior LA, Andrade EF, Rezende RP, et al. Inhibition of Staphylococcus aureus biofilm by Lactobacillus isolated from fine cocoa. BMC Microbiol. 2016;16:250.

3. Zhang W, Deng X, Zhou X, Hao Y, Li Y. Influence of Helicobacter pylori culture supernatant on the ecological balance of a dual-species oral biofilm. J Appl Oral Sci. 2018;26:e20170113.

4. Zhao A, Zhu J, Ye X, Ge Y, Li J. Inhibition of biofilm development and spoilage potential of Shewanella baltica by quorum sensing signal in cellfree supernatant from Pseudomonas fluorescens. Int J Food Microbiol. 2016;230:73-80.

5. Amel AM, Farida B, Djamila S. Anti-adherence potential of Enterococcus durans cells and its cell-free supernatant on plastic and stainless steel against foodborne pathogens. Folia Microbiol (Praha). 2015;60:357-63.

6. Schoster A, Kokotovic B, Permin A, Pedersen PD, Dal Bello F, Guardabassi L. In vitro inhibition of Clostridium difficile and Clostridium perfringens by commercial probiotic strains. Anaerobe. 2013;20:36-41.

7. Chorianopoulos NG, Giaouris ED, Kourkoutas Y, Nychas GJ. Inhibition of the early stage of Salmonella enterica serovar Enteritidis biofilm development on stainless steel by cell-free supernatant of a Hafnia alvei culture. Appl Environ Microbiol. 2010;76:2018-22.

8. Chen YS, Wu HC, Kuo CY, Chen YW, Ho S, Yanagida F. Leucocin C-607, a Novel Bacteriocin from the Multiple-Bacteriocin-Producing Leuconostoc pseudomesenteroides 607 Isolated from Persimmon. Probiotics Antimicrob Proteins. 2018;10:148-56.

9. Kim DH, Jeong D, Song KY, Kang IB, Kim H, Seo KH. Culture supernatant produced by Lactobacillus kefiri from kefir inhibits the growth of Cronobacter sakazakii. J Dairy Res. 2018;85:98-103.

10. Pridmore RD, Pittet AC, Praplan F, Cavadini C. Hydrogen peroxide production by Lactobacillus johnsonii NCC 533 and its role in anti-Salmonella activity. FEMS Microbiol Lett. 2008;283:210-5.

11. Sambanthamoorthy K, Feng X, Patel R, Patel S, Paranavitana C. Antimicrobial and antibiofilm potential of biosurfactants isolated from lactobacilli against multi-drug-resistant pathogens. BMC Microbiol. 2014:14:197.

12. Lee JJ, Lim JJ, Kim DG, Simborio HL, Kim DH, Reyes AW, et al. Characterization of culture supernatant proteins from Brucella abortus and its protection effects against murine brucellosis. Comp Immunol Microbiol Infect Dis. 2014;37:221-8.

13. Makino S, Ikegami S, Kano H, Sashihara T, Sugano H, Horiuchi H, et al. Immunomodulatory effects of polysaccharides produced by Lactobacillus delbrueckii ssp. bulgaricus OLL1073R-1. J Dairy Sci. 2006;89:2873-81.

14. Bermudez-Brito M, Muñoz-Quezada S, Gomez-Llorente C, Romero F, Gil A. Lactobacillus rhamnosus and its cell-free culture supernatant differentially modulate inflammatory biomarkers in Escherichia colichallenged human dendritic cells. Br J Nutr. 2014;111:1727-37.

15. Silva M, Jacobus NV, Deneke C, Gorbach SL. Antimicrobial substance from a human Lactobacillus strain. Antimicrob Agents Chemother. 1987;31:1231-3.

16. Goldin BR, Gorbach SL, Saxelin M, Barakat S, Gualtieri L, Salminen S. Survival of Lactobacillus species (strain GG) in human gastrointestinal tract. Dig Dis Sci. 1992;37:121-28.

17. Szajewska H, Wanke M, Patro B. Meta-analysis: the effects of Lactobacillus rhamnosus GG supplementation for the prevention of healthcareassociated diarrhoea in children. Aliment Pharmacol Ther. 2011;34:1079-87.

18. Korpela K, Salonen A, Virta LJ, Kumpu M, Kekkonen RA, de Vos WM. Lactobacillus rhamnosus GG Intake Modifies Preschool Children's Intestinal Microbiota, Alleviates Penicillin-Associated Changes, and Reduces Antibiotic Use. PLoS One. 2016;11:e0154012.

19. Näse L, Hatakka K, Savilahti E, Saxelin M, Pönkä A, Poussa T, et al. Effect of long-term consumption of a probiotic bacterium, Lactobacillus rhamnosus GG, in milk on dental caries and caries risk in children. Caries Res. 2001;35:412-20.

20. Snydman DR. The safety of probiotics. Clin Infect Dis. 2008;46:S104-11. 
21. Jiang Q, Stamatova I, Kainulainen V, Korpela R, Meurman JH Interactions between Lactobacillus rhamnosus GG and oral micro-organisms in an in vitro biofilm model. BMC Microbiol. 2016;16:149.

22. Ross KF, Ronson CW, Tagg JR. Isolation and characterization of the lantibiotic salivaricin A and its structural gene salA from Streptococcus salivarius 20P3. Appl Environ Microbiol. 1993;59:2014-21.

23. Hyink O, Wescombe PA, Upton M, Ragland N, Burton JP, Tagg JR Salivaricin A2 and the novel lantibiotic salivaricin B are encoded at adjacent loci on a 190-kilobase transmissible megaplasmid in the oral probiotic strain Streptococcus salivarius K12. Appl Environ Microbiol. 2007;73:1107-13.

24. Barbour A, Tagg J, Abou-Zied OK, Philip K. New insights into the mode of action of the lantibiotic salivaricin B. Sci Rep. 2016;6:31749.

25. Ishijima SA, Hayama K, Burton JP, Reid G, Okada M, Matsushita Y, et al. Effect of Streptococcus salivarius K12 on the in vitro growth of Candida albicans and its protective effect in an oral candidiasis model. App Environ Microbiol. 2012;78:2190-9.

26. Fiedler T, Riani C, Koczan D, Standar K, Kreikemeyer B, Podbielski A. Protective mechanisms of respiratory tract streptococci against Strepcoccus pyogenes biofilm formation and epithelial cell infection. Appl Environ Microbiol. 2013;79:1265-76.

27. Di Pierro F, Colombo M, Zanvit A, Rottoli AS. Positive clinical outcomes derived from using Streptococcus salivarius K12 to prevent streptococcal pharyngotonsillitis in children: a pilot investigation. Drug Healthc Patient Saf. 2016;8:77-81.

28. Burton JP, Wescombe PA, Moore CJ, Chilcott CN, Tagg JR. Safety assessment of the oral cavity probiotic Streptococcus salivarius K12. Appl Environ Microbiol. 2006;72:3050-3.

29. Mathur H, Field D, Rea MC, Cotter PD, Hill C, Ross RP. Fighting biofilms with lantibiotics and other groups of bacteriocins. NPJ Biofilms Microbiomes. 2018;4:9.

30. Patenge N, Arndt K, Eggert T, Zietz C, Kreikemeyer B, Bader R, et al. Evaluation of antimicrobial effects of novel implant materials by testing the prevention of biofilm formation using a simple small scale medium-throughput growth inhibition assay. Biofouling. 2012;28:267-77.

31. Switalski LM, Rydén C, Rubin K, Ljungh A, Höök M, Wadström T. Binding of fibronectin to Staphylococcus strains. Infect Immun. 1983;42:628-33.

32. Christensen GD, Simpson WA, Younger JJ, Baddour LM, Barrett FF, Melton DM, et al. Adherence of coagulase-negative staphylococci to plastic tissue culture plates: a quantitative model for the adherence of staphylococci to medical devices. J Clin Microbiol. 1985;22:996-1006.

33. Christensen GD, Baldassarri L, Simpson WA. Methods for studying microbial colonization of plastics. Methods Enzymol. 1995;253:477-500.

34. Redanz S, Standar K, Podbielski A, Kreikemeyer B. Heterologous expression of $s a h H$ reveals that biofilm formation is autoinducer-2-independen in Streptococcus sanguinis but is associated with an intact activated methionine cycle. J Biol Chem. 2012;287:36111-22.

35. Gómez-Suárez C, Busscher HJ, van der Mei HC. Analysis of bacterial detachment from substratum surfaces by the passage of air-liquid interfaces. Appl Environ Microbiol. 2001;67:2531-7.

36. Stepanović S, Vuković D, Hola V, Di Bonaventura G, Djukić S, Cirković I, et al. Quantification of biofilm in microtiter plates: overview of testing conditions and practical recommendations for assessment of biofilm production by staphylococci. APMIS. 2007;115:891-9.

37. Merritt JH, Kadouri DE, O'Toole GA. Growing and analyzing static biofilms. Curr Protoc Microbiol. 2005; Chapter 1:Unit 1B.1

38. Macià MD, Rojo-Molinero E, Oliver A. Antimicrobial susceptibility testing in biofilm-growing bacteria. Clin Microbiol Infect. 2014;20:981-90.

39. Doll K, Jongsthaphongpun KL, Stumpp NS, Winkel A, Stiesch M. Quantifying implant-associated biofilms: comparison of microscopic, microbiologic and biochemical methods. J Microbiol Meth. 2016;130:61-8.

40. Ommen P, Zobek N, Meyer RL. Quantification of biofilm biomass by staining: non-toxic safranin can replace the popular crystal violet. J Microbiol Meth. 2017;141:87-9.

41. Klinger-Strobel M, Stein C, Forstner C, Makarewicz O, Pletz MW Effects of colistin on biofilm matrices of Escherichia coli and Staphylococcus aureus. Int J Antimicrob Agents. 2017;49:472-9.

42. Varma P, Nisha N, Dinesh KR, Kumar AV, Biswas R. Anti-infective properties of Lactobacillus fermentum against Staphylococcus aureus and Pseudomonas aeruginosa. J Mol Microbiol Biotechnol. 2011;20:137-43.

43. Beloin C, Renard S, Ghigo JM, Lebeaux D. Novel approaches to combat bacterial biofilms. Curr Opin Pharmacol. 2014;18:61-8.

44. Charlier C, Cretenet M, Even S, Le Loir Y. Interactions between Staphylococcus aureus and lactic acid bacteria: an old story with new perspectives. Int J Food Microbiol. 2009;131:30-9.

45. Bhattacharya M, Wozniak DJ, Stoodley P, Hall-Stoodley L. Prevention and treatment of Staphylococcus aureus biofilms. Expert Rev Anti Infect Ther. 2015;13:1499-1516.

46. Schwarz F, Schmucker A, Becker J. Efficacy of alternative or adjunctive measures to conventional treatment of peri-implant mucositis and peri-implantitis: a systematic review and meta-analysis. Int J Implant Dent 2015;1:22.

47. Flichy-Fernández AJ, Ata-Ali J, Alegre-Domingo T, Candel-Martí E, Ata-Ali F, Palacio JR, et al. The effect of orally administered probiotic Lactobacillus reuteri-containing tablets in peri-implant mucositis: a double-blind randomized controlled trial. J Periodontal Res. 2015;50:775-85.

48. Hallström H, Lindgren S, Widén C, Renvert S, Twetman S. Probiotic supplements and debridement of peri-implant mucositis: a randomized controlled trial. Acta Odontol Scand. 2016;74:60-6.

49. Mongardini C, Pilloni A, Farina R, Di Tanna G, Adjunctive ZB, Farina R. Adjunctive efficacy of probiotics in the treatment of experimental periimplant mucositis with mechanical and photodynamic therapy: a randomized, cross-over clinical trial. J Clin Periodontol. 2017;44:410-7.

50. Vuotto C, Longo F, Donelli G. Probiotics to counteract biofilmassociated infections: promising and conflicting data. Int $\mathrm{J}$ Oral Sci. 2014;6:189-94

51. Gan BS, Kim J, Reid G, Cadieux P, Howard JC. Lactobacillus fermentum RC-14 inhibits Staphylococcus aureus infection of surgical implants in rats. Infect Dis. 2002;185:1369-72.

52. Zhou B, Zhang D. Antibacterial effects of bacteriocins isolated from Lactobacillus rhamnosus (ATCC 53103) in a rabbit model of knee implant infection. Exp Ther Med. 2018;15:2985-9. 